\title{
Doenças crônicas, problemas crônicos: encontros e desencontros com os serviços de saúde em itinerários terapêuticos de homens
}

rurais'

\section{Chronic diseases, chronic problems: agreements and disagreements with health services in therapeutic itineraries of rural men}

\author{
Andreia Burille \\ Doutoranda em Enfermagem. Enfermeira vinculada ao Grupo \\ Hospitalar Conceição. \\ Endereço: Rua General Caldwell, I.316/205, Menino Deus, CEP \\ 90050-130, Porto Alegre, RS, Brasil. \\ E-mail: andreiaburilleळyahoo.com.br \\ Tatiana Engel Gerhardt \\ Pós-doutora em Antropologia Visual. Professorada Universidade \\ Federal do Rio Grande do Sul. \\ Endereço: Rua São Manoel, 963, Rio Branco, CEP 90620-110, Porto \\ Alegre, RS, Brasil. \\ E-mail: tatiana.gerhardtळufrgs.br \\ I Artigo original da dissertação "Itinerários terapêuticos de ho- \\ mens em situação de adoecimento crônico: (des) conexões com \\ o cuidado e arranhaduras da masculinidade" (2012).
}

\section{Resumo}

Apresenta-se uma análise do sistema de cuidado profissional a partir de itinerários terapêuticos de homens em situação de adoecimento crônico. Trata-se de uma pesquisa qualitativa, descritiva e exploratória realizada em uma comunidade rural, situada num município da metade Sul do Rio Grande do Sul. Para a geração de dados, empregaram-se entrevistas semiestruturadas, grupo focal, diários de campo e observação não participante, no decorrer dos meses de janeiro a julho de 2011. Como técnica de análise, utilizou-se análise temática com triangulação de dados. Os achados apresentam diferentes itinerários terapêuticos traçados de acordo com a doença crônica vivenciada ou agudizada. Também evidenciam questões que permeiam as construções sociais da masculinidade e problemas crônicos de acesso aos serviços de saúde pela população rural. Revelou-se ao longo dos itinerários terapêuticos que o cuidado requerido pela situação de adoecimento crônico pode repercutir em diversas interfaces do cotidiano, tornando esse vivenciar um problema crônico que extrapola as dimensões biológicas da doença. Para os comentários finais, aponta-se a necessidade de mobilizar esforços para melhorar o acesso e principalmente para promover acessibilidade dos homens rurais aos serviços de saúde. Além disso, ressalta-se a necessidade de investir em ações e práticas que trabalhem com as questões que permeiam a masculinidade e sua relação com o cuidado em saúde, especialmente no vivenciar uma doença crônica, 
assim como mobilizar esforços para promoção de posturas profissionais mais inclusivas e humanizadas, que possibilite que os sujeitos masculinos sintam-se pertencentes aos espaços de saúde.

Palavras-chave: Saúde do Homem; Acesso aos Serviços de Saúde; Masculinidade; Saúde da População Rural.

\section{Abstract}

An analysis of the professional system of care is presented from therapeutic itineraries of men in situations of chronic illness. It is a qualitative, descriptive and exploratory research held in a rural community, located in a town of the southern half of Rio Grande do Sul. To generate data, semi-structured interviews, focus groups, field diaries and non-participant observation were used, during the months of January to July 2011. As analysis technique, thematic analysis was used with data triangulation. The findings show different therapeutic itineraries drawn according to experienced chronic or acute disease. They also evidence issues that permeate the social constructions of masculinity and chronic problems of access to health services for the rural population. It was revealed over the therapeutic itineraries that the care required by the situation of chronic illness can impact on various interfaces of everyday life, making this experience a chronic problem that extrapolates the biological disease. For final comments, the need to mobilize efforts is pointed to improve the access and mainly to promote accessibility of rural men to health services. Moreover, it emphasizes the need to invest in actions and practices that work with issues that permeate masculinity and its relationship to health care, especially in experiencing a chronic disease, as well as mobilize efforts to promote professional attitudes more inclusive and humanized, enabling the male subjects feel owned to health areas. Keywords: Men's Health; Access to Health Services Masculinity; Rural Health. 


\section{Introdução}

Compreender as conexões entre homens e saúde consiste em um desafio necessário para a promoção de uma atenção humanizada, acessível, que contemple as singularidades masculinas e que seja capaz de tornar essa busca por cuidado uma prática cotidiana, sem sofrimento ou pressão. Um desafio igualmente importante talvez seja a proposta de pensar esses vetores no espaço rural, pois se homens que residem no meio urbano tendem a buscar os serviços de saúde somente quando apresentam agudização dos problemas, para aqueles que residem no meio rural, os empecilhos para essa procura podem ser potencializados, em virtude de este espaço apresentar maiores lacunas referentes à atenção em saúde.

Sabe-se que, embora tenha ocorrido nos últimos anos uma expansão dos serviços de saúde, em especial ao que se remete a atenção básica (Brasil, 2012), algumas comunidades rurais ainda não possuem unidades de saúde em seu território, demandando dos indivíduos o deslocamento até ao meio urbano para acessar o sistema de cuidado profissional. Todavia, acresça-se que a busca de cuidado também é moldada por outros vetores, entre eles, as construções de gênero. Assim, os homens que residem nessas comunidades rurais, além de transpor questões relacionadas ao acesso funcional e geográfico para acessar os serviços de saúde, podem se defrontar com prescrições da masculinidade hegemônica, que entende a busca por cuidado como sinal de fraqueza e medo (Gomes e col., 2007), tornando a situação de adoecimento crônico um problema crônico, na medida em que esta requer a busca de cuidado em diferentes momentos.

Estudos comparativos de homens e mulheres têm comprovado o fato de que os homens são mais vulneráveis às doenças, sobretudo às enfermidades graves e crônicas, e que morrem mais precocemente do que as mulheres (Courtenay, 2000; Laurenti e col., 2005). Além disso, autores apontam que diferentemente das mulheres, homens não buscam os serviços de atenção primária e adentram no sistema de saúde nos níveis de cuidado com maior complexidade (Pinheiro e col., 2002; Figueiredo, 2005; Favorito e col., 2008; Brasil, 2008).

Outros trabalhos revelam questões relacionadas à construção social da masculinidade como fator decisivo para essa entrada tardia dos homens aos serviços de saúde, pois buscar cuidado em saúde iria aproximá-los de um espaço de representações de feminilidade (Gomes e col., 2007; Burille, 2009). Igualmente assinalam que as motivações pela busca por cuidado também se diferem, uma vez que as mulheres vão mais aos serviços de saúde com intuito de realizar exames de rotinas e ações preventivas, já os homens procuram auxílio por motivo de doença (Pinheiro e col., 2002; Toneli e col., 2010).

Nesse sentido, o cenário atual traz a necessidade de pensar a saúde da população masculina mais amplamente, pois tão importante quanto conhecer as causas e determinantes dos problemas de saúde, é identificar e explorar os sentimentos e reações manifestadas pelos indivíduos ao se deparem frente a frente com o adoecimento, assim como saber quando e quais estratégias estes mobilizam para resolvê-los e de que forma as fazem.

Ao perceberem-se adoecidos e ao mobilizarem-se para buscar cuidados, os indivíduos encontram diferentes práticas em saúde e sistemas de cuidado, com os quais podem desenhar múltiplas trajetórias (assistenciais ou não, incluindo diferentes sistemas de cuidado) em prol das necessidades de saúde, das disponibilidades de recursos sociais existentes sob a forma de redes sociais formais e informais - e da resolutividade obtida (Gerhardt e col., 2009). Essas múltiplas trajetórias em busca de cuidado configuram Itinerários Terapêuticos (ITs).

A investigação dos itinerários terapêuticos enquanto ferramenta teórico- metodológica se constitui como uma prática potencialmente reveladora e eficaz para compreender a complexidade de buscar cuidado. Além disso, os ITs ofertam uma avaliação do sistema profissional levando em consideração as dimensões subjetivas e não apenas indicadores de desempenho, que dificilmente dão conta da complexidade da vida cotidiana e das suas repercussões na saúde.

No vivenciar uma situação de adoecimento crônico, definida neste artigo como o processo no qual o indivíduo que a vivencia atribui significados socialmente reconhecidos a suas disfunções ou a seu estado patológico (Gerhardt e col., 2009, p. 296), o estudo dos itinerários terapêuticos ganha contornos especiais por englobar diferentes formas 
de cuidados mobilizados ao longo do tempo e as diversas interfaces que permeiam o vivenciar uma condição crônica, não encontradas em problemas de saúde com manifestação aguda.

Assim, o alinhamento entre itinerários terapêuticos com homens em situação de adoecimento crônico e o cenário rural vem inspirado em Toneli e colaboradores (2010) que enfatizam que buscar conhecer as explicações presentes em discursos masculinos sobre a procura por serviços de saúde, sua representação sobre esses serviços e relações que interagem nesse complexo sistema apresenta-se como um caminho promissor na discussão sobre as dificuldades, os obstáculos e as resistências associadas à saúde dos homens. De tal modo, este artigo busca apresentar uma avaliação do sistema de cuidado profissional a partir de itinerários terapêuticos de homens em situação de adoecimento crônico residentes em uma comunidade rural.

\section{Caminhos da pesquisa}

Os dados apresentados neste artigo integram a dissertação "Itinerários terapêuticos de homens em situação de adoecimento crônico: (des)conexões com o cuidado e arranhaduras da masculinidade”. Considerando os itinerários terapêuticos singulares, um entendimento aprofundado da realidade a ser investigada teria que ser alcançado e, para isso, optou-se por trabalhar com pesquisa qualitativa, pois qualquer investigação que vise um estudo mais amplo não pode ficar restrita apenas a números (Minayo, 2010). A observação, o registro e a análise de fatos sem intervir sobre eles conferiram ao estudo um caráter descritivo. Já o levantamento de informações com a finalidade de conhecer melhor esse fenômeno e o intuito de descobrir novos caminhos o caracterizou como exploratório (Cervo e Bervian, 1996; Severino, 2007).

O estudo foi realizado na comunidade rural Rincão dos Maia, Canguçu, Rio Grande do Sul. Justifica-se a escolha desta comunidade em virtude da existência de um banco de dados que disponibilizava, além de uma caracterização dos moradores, a autorreferência de condições crônicas, independentemente de esta referência ter vindo do sistema profissional para o entrevistado ou de sua própria construção subjetiva, ponto importante no estudo dos itinerários terapêuticos, pois se tinha o objetivo de não localizar os participantes por indicação de serviço e/ou profissionais de saúde.

A partir da construção de um novo banco de dados contendo apenas homens em situação de adoecimento crônico evidenciou-se um maior número de sujeitos alocados no grupo de problemas cardiovasculares. Considerando isso, aliado à diversidade de situações presentes e tendo em vista que as condições cardiovasculares correspondem à segunda causa de morbidade e mortalidade masculina, ficando atrás somente das causas externas, optou-se por trabalhar com esse universo que correspondia a um total de 20 homens.

Dos 20 possíveis entrevistados, 12 participaram da construção de seus itinerários terapêuticos. Foram excluídos do estudo dois que não podiam se comunicar em função de sequelas dos problemas crônicos; três que não foram encontrados em casa nas etapas de campo; um que havia falecido; um que não residia mais na comunidade e um que não referiu condição crônica. Com relação ao número de entrevistados, é importante destacar que o estudo proposto não buscou representatividade numérica e sim um aprofundamento da temática estudada (Minayo, 2010).

A geração de dados se concentrou nos meses de janeiro, junho e julho de 2011, e foi mediada a partir de entrevistas semiestruturadas, diário de campo, observação não participante e grupo focal, sendo algumas dessas técnicas utilizadas no decorrer das três etapas da pesquisa. A primeira incursão na comunidade ocorreu em janeiro de 2011, mês em que foi realizado o convite para participar do estudo e direcionadas as primeiras visitas e observações do cotidiano. Nesses encontros, duas entrevistas, nas quais os entrevistados contaram seus itinerários terapêuticos, falaram sobre as redes sociais e concepções de saúde e doença, foram gravadas. Diários de campo eram feitos diariamente. Nos meses seguintes, os primeiros dados gerados foram organizados e analisados.

A segunda etapa desenvolveu-se em junho, com uma nova incursão na comunidade rural. Com o enfoque nos períodos de silenciamento das condições crônicas, mais uma entrevista foi realizada e 
os itinerários terapêuticos construídos na primeira etapa foram apresentados aos entrevistados para validação dos caminhos de cuidado. Diários de campo e observação das estratégias de cuidado nos espaços domiciliares também compuseram essa etapa, que teve pelo menos duas visitas a cada homem participante.

Em julho, retornou-se novamente à comunidade com o intuito de realizar mais visitas e ampliar a observação-participante com foco nas redes sociais. Neste mês, realizaram-se mais duas visitas aos homens participantes do estudo e organizou-se um grupo focal, que teve por objetivo aprofundar as construções sociais atribuídas aos homens e os reflexos dessas na relação com cuidado em saúde. Os dados gerados pelas entrevistas semiestruturadas e pelo grupo focal foram transcritos, identificados e organizados com o auxílio do software NVivo8. Os diários de campo e de observações também foram digitados, identificados e organizados de acordo com cada etapa da pesquisa.

Os itinerários terapêuticos foram construídos com a triangulação dos dados, o que permitiu que não ficassem restritos apenas ao discurso e, sim, que também englobassem as práticas adotadas, ou não, por eles. Para sua apresentação em dimensões espaciais e temporais utilizou-se o software de design SmartDraw-2009. Com isso, prosseguiu-se com análise de dados conforme a técnica de análise temática proposta por Minayo (2010), que se estrutura em três etapas: pré-análise; exploração do material; tratamento dos resultados obtidos e interpretação. Os dados obtidos por meio da observação não participante e dos diários de campo complementaram as análises, que posteriormente foram completadas com leituras e reflexões e ilustraram algumas das situações vivenciadas no decorrer da pesquisa de campo.

O estudo contou com um teste piloto visando o aperfeiçoamento dos instrumentos a serem utilizados e obedeceu à Resolução 196/96 do Conselho Nacional de Saúde, que trata dos aspectos éticos de pesquisas envolvendo seres humanos. Todos os entrevistados foram assegurados por meio do Termo de Esclarecimento e Consentimento Pós-Esclarecimento. A proposta, como integrante do projeto de pesquisa "Sistemas locais de saúde, determinantes sociais e itinerários terapêuticos de pacientes com doenças crônicas não transmissíveis", foi submetida ao Comitê de Ética em Pesquisa da Universidade Federal do Rio Grande do Sul (CEP/UFRGS), com o

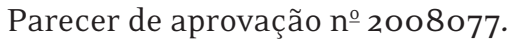

\section{Resultados}

\section{O Sistema de cuidado profissional em Canguçu}

Para melhor contextualizar os resultados apresentados, uma breve contextualização do sistema de cuidado profissional de Canguçu será apresentada.

Sabe-se que as populações rurais, em muitos municípios, ainda se encontram desassistidas de atenção profissional de saúde, tendo que se deslocar até a área urbana em busca desta forma de cuidado. Em Canguçu não é diferente, o município conta com 27 estabelecimentos de saúde, todos localizados na área urbana, embora mais de $60 \%$ de sua população resida em áreas rurais. Esses serviços se encontram distribuídos em cinco centros de saúde, 13 unidades básicas (postos), duas clínicas especializadas, um hospital geral com pronto atendimento, cinco unidades de apoio diagnose e terapia, e uma unidade de vigilância em saúde, sendo que 21 realizam atendimento de demanda espontânea, um atende serviço por demanda referenciada e cinco por demanda referenciada e espontânea (Gerhardt e col., 2011).

Os moradores do Rincão dos Maia, até final de 2008 , tinham atendimento na comunidade, pois ela possuía um posto de saúde que foi construído em parceria com o poder público. Os profissionais que ali atuavam, um médico, um técnico de enfermagem e um dentista, eram contratados pela associação comunitária, que mantinha um convênio com a prefeitura do município. Mas com término do convênio, estes deixaram de atender e a comunidade passou a receber atendimento do posto itinerante ou unidade móvel que percorre as áreas rurais do município. Assim, a cada 15 ou 3 o dias os moradores do Rincão dos Maia recebem a visita de uma equipe de saúde. No entanto, essa modalidade de serviço não consegue atender à demanda da população, restando como única alternativa a busca por este tipo de cuidado na cidade.

Com relação à oferta de cuidado nos sistemas popular e informal, pode-se apontar a presença de 
duas benzedeiras na comunidade, uma inclusive visitada na primeira etapa da pesquisa, quando a pesquisadora acompanhou um adoecimento. Na construção dos itinerários terapêuticos, foram citados pelos entrevistados que construíram buscas plurais, um curandeiro de Santa Catarina, que vem ao município atender de tempo em tempo, uma benzedeira de uma comunidade rural vizinha e um benzedor/curandeiro de Pelotas. Já sobre as redes de cuidado informais, Ruiz (2013) ao realizar um trabalho na comunidade, evidenciou forte vínculo entre vizinhos, amigos e parentes, que atuam em diferentes formas, disponibilizando informações até ajudas materiais, auxiliando na constituição de itinerários terapêuticos nas situações de agudização e silenciamento das condições crônicas.

\section{Os itinerários terapêuticos de homens em situação de adoecimento crônico}

A análise dos itinerários terapêuticos de homens em situação de adoecimento crônico revelou dois padrões de busca de cuidado: um direcionado para o cuidado oferecido pelo sistema profissional e outro focado em uma busca plural de cuidado, contemplando os sistemas informal, popular e profissional em diferentes combinações e situações. Assim, diante deste cenário questionou-se: o que teria definido a utilização de um ou mais sistemas de cuidado? Por que alguns dos entrevistados optaram por utilizar apenas o sistema profissional e outros não?

Entre os doze entrevistados, cinco deles apresentavam apenas problemas cardiovasculares e mencionaram utilizar o cuidado oferecido pelo sistema profissional no adoecimento. Quando questionados sobre o motivo de escolher este sistema, responderam que, para problemas de coração, pressão alta, considerados sérios, o cuidado oferecido pelo sistema informal, constituído pela família, amigos, chás, entre outros, não era apropriado e que nem o sistema popular (benzedeiras, curandeiros, espiritualistas, etc.) poderia solucioná-los, restando como único recurso o sistema profissional.

No grupo de homens que construíram itinerários terapêuticos plurais (sete), seis deles relataram problemas cardiovasculares associados a outras condições crônicas. Quando interrogados sobre as escolhas de sistemas de cuidado diferenciados, estes responderam que buscaram o mais adequado para lidar com o problema vivenciado: assim para as doenças classificadas como sérias, as manifestações exigiram cuidado profissional; para os sintomas e condições tidas por eles como simples, estas foram remediadas pelo sistema informal e popular.

Achado semelhante foi apontado por Trad e colaboradores (2010), ao realizarem um estudo etnográfico com famílias de classes populares, do bairro Boca do Rio, na cidade de Salvador. Ao investigar os enfrentamentos dos problemas de saúde, em especial, a hipertensão arterial, a pesquisa evidenciou que as famílias cuidavam dos problemas tidos como "leves" em casa, por meio de mudança na alimentação e outras formas de cuidados populares e informais. Já para os classificados como "graves", como a hipertensão arterial, mobilizavam o sistema formal de saúde, reconhecendo que as demais formas de cuidado poderiam ser coadjuvantes.

A íntima relação entre trabalho e saúde foi elencada pelos entrevistados ao relacionarem as doenças sérias com as condições que impedem a realização das atividades cotidianas, sendo a incapacidade para o trabalho o principal disparador pela busca pelo cuidado profissional. Também ao longo dos itinerários terapêuticos observou-se que alguns homens já estavam apresentando sinais e sintomas de que não estavam bem, mas não compartilharam, pensando que seria apenas um mal-estar passageiro, vindo a falar e buscar auxílio somente quando agudizaram.

Entre as atividades conferidoras de saúde no espaço rural, encontra-se a capacidade de trabalhar. De acordo com Gerhardt e colaboradores (2009), desde jovem o indivíduo é inserido no cotidiano do trabalho rural. Plantar, colher e produzir em prol da subsistência e/ou lucro são práticas que fazem parte do dia a dia e que são passadas de geração a geração como forma de pertencimento àquele meio e estão diretamente relacionadas com o papel masculino já que ofertam status e valor aos homens. Assim, o homem em situação de adoecimento crônico, quando se percebe incapacitado para as atividades cotidianas, passa a vivenciar de um espaço marginal, questionamentos/repercussões sobre o que está definido socialmente como ser homem e ser trabalhador.

Segundo Nardi (1998), a capacidade e as habilidades para o trabalho são elementos constituintes 
do ethos masculino nas classes trabalhadoras, o que também foi identificado por Oliveira (1998), que ao realizar um trabalho com homens e mulheres em idade fértil, em quatros vilas de Porto Alegre, observou, nos discursos masculinos, maior associação entre doença e não poder trabalhar. Entre as justificativas mais frequentes, o autor pontuou falas que indicavam que o homem deve prover o sustento da família e trabalhar independentemente das circunstâncias, pois perder um dia de trabalho representa preocupações financeiras, e ao mesmo tempo, ser fraco.

As observações realizadas junto ao grupo também demonstraram que a presença de mais condições crônicas associadas potencializou a busca por cuidado plural, uma vez que estes apresentaram momentos de agudização e manifestações das diversas condições crônicas que no seu vivenciar acabaram, às vezes por desejo ou por necessidade, mobilizando e envolvendo-os mais no cuidado do que aqueles que conviviam somente com os problemas cardiovasculares.

Outros estudos direcionados para itinerários terapêuticos apontam também a existência da classificação de doenças em sérias ou simples como norteadoras das práticas de cuidado. Nestes itinerários, a primeira escolha de cuidado para condições simples foi o setor informal, por meio de automedicação; caso os sintomas não aliviassem, o setor profissional foi acionado, seguido pelo setor popular. Já, no caso de doenças consideradas sérias, a primeira escolha foi sempre o setor profissional (Gerhardt, 2006; Souza e Lopes, 2007; Roese e Gerhardt, 2008). Para essa classificação, Gerhardt (2006) enfatiza que os indivíduos não mobilizam apenas suas experiências e informações acumuladas, mas também o discurso das racionalidades médicas e populares em saúde.

No Rincão dos Maia, o cuidado profissional fez-se presente em todas as trajetórias masculinas de busca por cuidado, ora como única escolha, ora como escolha em algum momento durante a vivência da situação de adoecimento crônico. Evidenciou-se seu acionamento, na grande maioria, em episódios de agudização das condições crônicas, fornecendo a essa busca um ritmo intenso que se diferencia dos momentos de silenciamentos/estabilidade, nos quais a busca pelo sistema profissional ocorreu de modo pontual, em geral por meio de consultas médicas.
Neste contexto, a influência da medicalização da saúde, aqui entendida como processo pelo qual os modos de vida são apropriados pela medicina, modificando conceitos, regras de higiene, normas de moral e costumes prescritos - sexuais, alimentares, de habitação - e de comportamentos sociais (Luz, 1988), também precisa ser considerada, uma vez que muitos dos entrevistados referiram jargões pulverizados na mídia por profissionais de saúde para justificar sua busca de cuidados neste sistema, ofertando-lhe, ao mesmo tempo, um status superior às demais formas de cuidado, como se pode acompanhar na fala de João ao referir-se sobre seu problema de saúde:

[...] quando as coisas estão ruim tem que buscar o médico, coração não dá pra esperar, vai que seja infarte, (sic) se tomar "sustrato" (Sustrate) consegue reverter, né, agora se não for, aí... (João, 56 anos, agricultor).

Na agudização do problema de saúde vivenciado, pessoas e famílias costumam imprimir um ritmo frenético às suas trajetórias de busca por cuidado no subsistema profissional, pois a situação requer, muitas vezes, intervenção profissional. Já, nos períodos de estabilidade, a busca pelos serviços e profissionais de saúde se torna mais esporádica e, quando ocorrem, são rotineiramente realizadas de acordo com o modo de organização de oferta de insumos pelos serviços, tais como medicação mensal, imprimindo ritmo de rotina a essa busca (Araújo e col., 2009).

Com relação às categorias acesso e acessibilidade aqui apreendidas como a entrada no serviço (Travassos e Martins, 2004) e à facilidade pela qual as pessoas podem obter o cuidado (Donabedian, 2003), observou-se uma procura intensa pelo pronto-socorro, por atendimentos médicos em consultórios particulares e no ambulatório de saúde do sindicato rural do município de Canguçu. Sobre as motivações para a busca de tais serviços, os discursos masculinos apontaram o pronto-socorro como um serviço que atende 24 horas, gratuito, que oferece exames e medicações, sendo rápido e resolutivo para a maioria das demandas ali trazidas. Assim, segundo muitos dos entrevistados, tais características tornam este serviço "ideal" à população masculina, em especial 
para os homens que residem no meio rural, como ilustra a fala de Danilo:

Se tá meio ruim a gente aguenta, agora se tá muito ruim a gente vai no pronto-socorro, é muito bom aquele pronto-socorro do hospital [...] ali não precisa sair cedo, deixar o trabalho na lavoura, a hora que chegar lá é atendido, sai agora, espera uns minutos $e$ é atendido. Agora, no posto, não, chega ali pelas nove horas e tem que esperar até de tarde para tirar uma ficha para de tarde, perde muito tempo, nem sabe se vai conseguir esabe como éhomem (Danilo, 59 anos, aposentado).

Homem não fica perdendo tempo, homem vai lá e resolve, essas coisas demoradas é para mulher que tem mais paciência, o cara tem tudo para administrar (Rodolfo, 45 anos, agricultor e diarista/ diário de Campo 3).

Uma pesquisa realizada por Roese e Gerhardt (2008) sobre fluxos e acesso de usuários a serviços de saúde de média complexidade no Município de Camaquã/Rio Grande do Sul, evidenciou que a população residente na área rural utilizava mais o serviço de emergência do que os residentes na área urbana. Para as autoras tal fato pode estar relacionado com o acesso geográfico e com a falta de acesso a outras formas de atenção à saúde, já que os serviços de saúde se organizam em sua grande maioria, para não dizer, em sua totalidade, no meio urbano. No município de Canguçu, evidenciou-se pelo Sistema de Informação da Atenção Básica (SIAB) ampla utilização de serviços de média e alta complexidade para ações sensíveis à atenção básica (Gerhardt e col., 2011). Assim, pode-se dizer que os serviços de emergência, muitas vezes, diferentemente da atenção básica, tornam-se porta de entrada da população rural na busca pelo cuidado profissional.

Homens são mais vulneráveis às doenças graves e crônicas e, diferentemente das mulheres, não buscam os serviços de atenção primária, adentrando no sistema de saúde nos níveis de cuidado ambulatorial e hospitalar de média e alta complexidade, o que tem por consequências o agravamento da patologia gerado pela demora na busca por cuidado e a determinação de maior ônus para o sistema de saúde (Figueiredo, 2005; Favorito e col., 2008; Brasil, 2008). Em geral, estes tendem a justificar a presença mais esporádica nestes serviços como relacionada à demora do atendimento e à falta de recursos materiais e humanos, em especial, dos profissionais médicos, tidos como referência de cuidado de qualidade. Por essas razões preferem buscar atendimento em hospitais e prontos-socorros, pois são serviços rápidos e pontuais (Schraiber e col., 2010).

A utilização dos consultórios particulares foi justificada pelo atendimento dispensado pelo profissional médico que, segundo os homens entrevistados, é mais aprimorado, o profissional de saúde tem mais tempo para conversar, a gente tá pagando, pode exigir (Benedito, 62 anos, aposentado/ Diário de Campo 4), e também em função dos vínculos para com o profissional acionado. Tal fala mencionada por Benedito nos remete a pensar sobre a ideia que muitos usuários têm do Sistema Único de Saúde (SUS) e do atendimento por ele oferecido, que por ser gratuito é percebido e, em algumas vezes, porque não dizer remetido pelo profissional como um favor e não como um direito legalmente adquirido, fazendo com que muitos usuários não se sintam encorajados a questionar a qualidade do cuidado ofertado.

Já o ambulatório de saúde do sindicato rural do município foi apontado como estratégia de cuidado tanto nos momentos de agudização, quanto nos de silenciamento. Com o convênio, o acesso aos cuidados profissionais ocorre sem longas esperas e com custos acessíveis, sem contar a identificação com o serviço que é direcionado para agricultores. Nas entrevistas o vínculo com o ambulatório era associado ao atendimento dispensado, uma vez que os entrevistados sentiam-se pertencentes àquele espaço.

Reportando-se à utilização da atenção básica para o cuidado em saúde, os homens apontaram como pontos decisivos para a não busca destes serviços a demora no atendimento, a falta de fichas e o horário de atendimento que não condiz com a necessidade de muitos homens da comunidade que necessitam se deslocar para a cidade de ônibus. Todavia, pontuaram que a existência de unidades básicas nas comunidades rurais poderia contribuir efetivamente para a promoção da saúde da população que ali reside. Como exemplo disso, ilustraram algumas situações importantes que foram acolhidas e cuidadas na unidade de saúde que tinham na comunidade até 2008. 
Ao realizar uma pesquisa multicêntrica sobre homens e serviços de atenção básica, Couto e colaboradores (2010) trazem importantes apontamentos que fomentam reflexões para as falas dos entrevistados deste estudo. Na pesquisa citada, os autores apontam o reforço da feminilização dos ambientes, tanto por materiais voltados para educação em saúde, como decorativos, destacando que embora haja um movimento para inclusão de gênero nos informes de saúde nacionais, isso ainda não alcança as equipes dos serviços em suas produções locais. Além disso, pontuam que existe maior procura dos homens nas unidades que possuem horário ampliado, endossando a discussão acerca do trabalho como aspecto que restringe o acesso e o uso dos serviços pelos homens (Gomes e col., 2007) e finalizam evidenciando um movimento constituído por poucas intervenções direcionadas ao público masculino e o não reconhecimento destes como usuários e sujeitos de cuidado.

Entrevistados sem meio de locomoção próprio relataram as dificuldades de conseguir atendimento, em especial, na atenção básica, pois são poucas as alternativas disponíveis: esperar o ônibus escolar que passa ao meio dia na comunidade e correr o risco de chegar à unidade e não ter fichas disponíveis para atendimento; pedir ou pagar para um vizinho ou amigo levar até a cidade ou em último caso ir caminhando mais de $14 \mathrm{~km}$. Tais colocações refletem a organização do Sistema Único de Saúde e os problemas crônicos de acesso às políticas públicas, e neste caso, de saúde, a que as populações rurais estão expostas. Por outro lado, apontam o importante papel das redes sociais em saúde, evidenciando a sua potencialidade na promoção de cuidado.

Os indivíduos que residem no meio rural tendem a avaliar com mais frequência seu estado de saúde como ruim e muito ruim do que as pessoas que residem na área urbana. Com relação às motivações para buscar cuidado, as pessoas que residem na área urbana buscam mais os serviços de saúde para realizar exames de rotina e de prevenção, enquanto que na área rural a principal motivação para a busca de cuidado são as doenças (Kassouf, 2005). Já Morais e colaboradores (2008), ao buscarem conhecer as condições de saúde e hábitos de vida de idosos residentes no meio rural, evidenciaram que a pior percepção da saúde é maior entre os homens, quando comparados às mulheres.

Ao falar dos encontros nos serviços de saúde, os entrevistados referiram que alguns profissionais não dedicam um tempo necessário para escutar, muitas vezes, nem suas demandas, que dirá as necessidades de saúde. E que quando a escuta ocorre, ela não se dá de maneira humanizada, enfatizando o diálogo e a troca de saberes. Ainda, afirmaram que já saíram dos serviços de saúde com dúvidas por medo de perguntar mais informações aos profissionais. A partir disso, pode-se se apontar que nos encontros (usuário-profissional), nos quais deveria ocorrer a construção do vínculo, de trocas, de valorização e de cuidado em seu sentido amplo, ocorrem desencontros, pois nem sempre o profissional se encontra sensibilizado e disponível para um encontro que vise atender tais necessidades.

Na construção dos ITs, a figura do médico surgiu como central no espaço de atenção profissional, sendo visto como principal fonte de cuidado dentro dos serviços de saúde. Os diálogos entre homens e profissionais revelados foram quase sempre dirigidos por queixas e demandas, e em alguns casos a ausência de acolhimento e de humanização teve presença marcante, como ilustra o relato de João, aqui trazido pela dimensão da situação vivenciada:

[...] vou dizer pra ti, eu não sei se a outra vez que tu teve aqui eu cheguei a falar contigo, eu fui num médico em Porto Alegre e perdi a caminhada. Se eu dizer pra ti que perdi a caminhada, fiz um exame de próstata lá, fui fazer [...] ele pediu todos os exames que eu tinha até agora, ninguém me falou em exame de próstata, nem de coração, nem de nada, pediram o exame eu fui lá fazer, eu vou lá, meu Deus, guria, tchê!, eu vou dizer pra ti, eu só não soltei os cachorros naquele médico porque, tu imagina, o homem com a esposa ir lá em Porto Alegre dentro do consultório do médico, esperar quanto tempo lá no consultório pro cara chegar e soltar as pata no cara! "Primeira coisa, todos exames."- Que exames? Doutor, ninguém me pediu exame! - "Mas então tu não trouxe exame? Tu veio fazer o que aqui?”- Vim fazer o exame, doutor, está aqui o exame, doutor. "Pela as calças, pela as calças, as calças no chão!", bem assim ele disse pra mim [...] Por gentileza nem mandou a minha mulher sair pro outro lado [...] 
Achei que nem... achei que nem ia lambuzar o dedo, não ia lambuzar, tchê! [...] Não, eu vou dizer pra ti, saí de lá assim indignado, indignadíssimo! [...] eu, como eu te disse, eu já venho sofrendo desde 2007, não acostumando, mas enfrentando os problemas com médico, [...] (João, 56 anos, agricultor).

Schraiber e colaboradores (2010), ao observar os encontros entre usuários e profissionais, identificou que os profissionais estão mais preocupados em oferecer uma resposta pronta e que tomam decisões voltadas a condutas já conhecidas e centradas na terapêutica de patologias. Nesses encontros ocorrem muitos encaminhamentos, muitos pedidos de exames e quase sempre há uma indicação de remédios; há também pouca exploração dos contextos de vida, pois as consultas com homens são diretas nas queixas e patologias, sendo comum ouvir usuários relatarem que o profissional nem sequer os olhou.

No que se refere à abordagem, Trad e colaboradores (2010), ao entrevistar famílias de classes populares, também apontam queixas relacionadas à falta de inclusão dos significados atribuídos pelos usuários aos sintomas, bem como os problemas de ordem familiar ou financeira que pudessem impactar sobre o seu estado de saúde ou fossem decorrentes da situação de adoecimento vivenciada, como por exemplo, a impossibilidade de trabalhar, que além das repercussões sociais, traz dificuldades de reprodução material das famílias.

Ainda com relação às barreiras institucionais (fatores relacionados aos serviços e profissionais) destaca-se que, para os homens entrevistados, o fato de existir mais profissionais mulheres trabalhando nos serviços de saúde não foi considerado um fator impeditivo para buscar esse cuidado, sendo que a maioria deles referiu preferir ser atendido por mulheres. Tal fato desperta atenção, pois vários estudos com homens residentes no meio urbano apontam que estes veem com impeditivo este fator, considerando os serviços de saúde como espaços feminilizados (Gomes e col., 2007; Figueiredo e Schraiber, 2011).

Talvez a preferência dos entrevistados em expor seus problemas para profissionais do sexo feminino esteja relacionada às questões que permeiam a masculinidade hegemônica, que no espaço rural parecem mais rígidas. Admitir a existência de um problema para outro homem, mesmo sendo este um profissional de saúde, pode ser visto como "uma falha da masculinidade," sem contar o medo de ser julgado e ou sofrer constrangimentos. Todavia, compartilha-se que, para o acolhimento dos homens nos serviços de saúde, é essencial uma mudança da postura prática de todos os profissionais, sejam eles homens ou mulheres (Figueiredo, 2005) para se promover de um cuidado humanizado que também considere a construção social das masculinidades e suas repercussões na saúde.

Arespeito da resolução e resolutividade na busca pelo cuidado, há de se pontuar a existência de lógicas diferenciadas que constroem essas noções, pois, enquanto os indivíduos buscam resolução para as suas necessidades, os serviços tendem a oferecer certa capacidade de resolutividade para as necessidades, recortadas em problemas de saúde (Bellato e col., 2009). Observou-se nos itinerários terapêuticos que nem sempre essa resolução do problema é alcançada na busca pelo cuidado profissional. Assim, na medida em que as respostas dadas pelos profissionais mostram-se parciais ou ineficientes, os indivíduos tendem a acionar novos dispositivos que impulsionam a busca por outros cuidados, que talvez possam oferecer resolução para seu problema de saúde.

Ampliando um pouco mais essa discussão, Gerhardt e colaboradores (2009) referem que ter acesso não garante que as necessidades serão satisfeitas, trazendo a acessibilidade para se referir às facilidades e dificuldades em buscar/receber cuidado (interação entre quem busca e quem oferece cuidado). Assim, definem acessibilidade como uma prática não normativa, de inter-relação e intersubjetividades, portanto uma prática que significa não só apenas o acesso dos usuários aos serviços de saúde, mas também a resolução das suas demandas e necessidades de saúde.

Com relação às repercussões da barreira sociocultural para o acesso e acessibilidade dos homens aos serviços de saúde, evidenciou-se no decorrer da pesquisa, que as questões relacionadas à masculinidade desempenharam papel importante na não busca por cuidado. Nas narrativas uma grande dificuldade de expressar o problema de saúde vivenciado pode ser identificada, pois para eles relatar o fato para a família e para a comunidade significava que, 
como homens, estavam fracassando. Além disso, as preocupações com a família, com os gastos das economias e/ou dívidas e até a necessidade de diminuir ou cessar o trabalho foram elementos elucidados para adiamento ao máximo pela busca por cuidado.

Quando questionados sobre o uso do sistema profissional antes de adoecer, os homens entrevistados revelaram que buscaram esse cuidado apenas em caso de acidentes na lavoura e ainda se este fosse considerado grave, como cortes, perfurações ou picadas de animais peçonhentos. E quando apresentavam alguma coisa considerada mais simples, esperavam melhorar sozinhos, se automedicavam ou usavam chás. A busca, segundo eles, por esse sistema de cuidado deu-se apenas com a agudização do problema de saúde. Assim, pode-se perceber que cuidar da saúde impõe condições que não combinam com a identidade masculina, pois o cuidado foi referenciado à figura feminina. Todavia, não se pode atribuir a baixa freqüência dos homens aos serviços de saúde somente às construções sociais de gênero, pois, como aponta Couto e colaboradores (2010), é preciso também considerar a sua baixa inclusão nas propostas assistenciais e gerenciais dos serviços de saúde. Dessa forma, entende-se que a resistência não se dá apenas por parte dos homens, mas também por uma lógica de produção e organização dos serviços que, muitas vezes, os invisibilizam.

Diante das colocações, pode-se inferir que o acesso (geográfico e funcional, mas também econômico e cultural) aos serviços de saúde pelos entrevistados nem sempre foi fácil. Há de se considerar nessa entrada aos serviços de saúde as longas distâncias até a cidade, a dificuldade de transporte e seu custo, conciliar as demandas do trabalho e conseguir superar as barreiras socioculturais que estruturam a masculinidade. Com relação à acessibilidade (resolutividade, cuidado em seu sentido amplo), ressalta-se que esta nem sempre esteve presente nos encontros entre profissionais de saúde e homens, como as falas trazidas ilustram. Em síntese, os itinerários terapêuticos de homens em situação de adoecimento crônico mostram que o acesso aos serviços de saúde, apesar das dificuldades aqui colocadas, é alcançado, no entanto, a acessibilidade e a resolução das demandas e necessidades nem sempre.

\section{Comentários finais}

A avaliação do sistema de cuidado profissional a partir dos itinerários terapêuticos de homens em situação de adoecimento crônico residentes em uma comunidade rural revela a importância de construir estratégias para atrair a população masculina aos serviços de saúde para então realizar práticas de prevenção de doenças e promoção da saúde, assim como instituir ações direcionadas à assistência, considerando as diferentes necessidades masculinas e determinantes e condicionantes da saúde.

Os achados apontam para necessidade de fortalecer os serviços em redes e garantir acesso, acessibilidade, responsabilização e resolução das demandas e necessidades masculinas que ali são compartilhadas. Também mostram que a organização de serviços em espaços rurais poderia contribuir para a promoção da saúde dessas populações, inclusive para os homens. Além disso, indicam que esforços devem ser mobilizados no cuidado em situação de adoecimento crônico, pois nesta condição que requer cuidado ao longo do tempo, o acesso e acessibilidade aos serviços de saúde tornam-se problemas crônicos, com potencial de intervir em outras interfaces do cotidiano.

Os itinerários terapêuticos ainda revelam a importância de trabalhar com as questões que permeiam a barreira sociocultural que estrutura a masculinidade e ressaltam a necessidade de uma postura profissional inclusiva, que possibilite que os sujeitos masculinos sintam-se pertencentes aos espaços de saúde e que ao mesmo tempo sejam vistos como sujeitos que necessitam de cuidados. Assim, conclui-se que não basta reconhecer que o homem tem direito à saúde, é preciso dar condições para que esses direitos sejam alcançados.

\section{Referências}

ARAÚJO, L. F. S.; BELLATO, R.; HILLER, M. Itinerários terapêuticos de famílias e redes para o cuidado na condição crônica: algumas experiências. In: PINHEIRO, R.; MARTINS, P. H. (Org.). Avaliação em saúde na perspectiva do usuário: abordagem multicêntrica. Rio de Janeiro: CEPESC, 2009. p. 203-214. 
BELLATO, R. et al. Itinerários terapêuticos de famílias e redes para o cuidado na condição crônica: alguns pressupostos. In: PINHEIRO, R.; MARTINS, P. H. (Org.). Avaliação em saúde na perspectiva do usuário: abordagem multicêntrica. Rio de Janeiro: CEPESC, 2009. p. 187-202.

BRASIL. Ministério da Saúde. Secretaria de Atenção à Saúde. Política Nacional de Atenção Integral à Saúde do Homem. Brasília, DF, 2008. Disponível em: <http://dtr2oo1.saude.gov.br/sas/ portarias/port2008/pt-o9-cons.pdf >. Acesso em: 1 maio 2010.

BRASIL. Ministério da Saúde. Secretaria de Atenção à Saúde. Departamento de Atenção Básica. Política Nacional de Atenção Básica. Brasília, DF, 2012. Disponível em: <http://189.28.128.100/dab/docs/publicacoes/ geral/pnab.pdf >. Acesso em: 22 ago. 2013.

BURILLE, A. Conhecendo as mudanças no cotidiano de homens com câncer: um olhar sobre a perspectiva de gênero. 2009. Monografia (Bacharelado em Enfermagem) -Faculdade de Enfermagem da Universidade Federal de Pelotas, Pelotas, 2009.

CERVO, A. L.; BERVIAN, P. A. Metodologia científica. São Paulo: Makron, 1996.

COURTENAY, W. Constructions of masculinity and their influence on men's well-being: a theory of gender and health. Social Science \& Medicine, Boston, v. 5o, n. 1, p. 1385-1401, 2000.

COUTO, M. T. et al. Men in primary healthcare: discussing (in) visibility based on gender perspectives. Interface: Comunicação, Saúde, Educação, Botacatu, v. 14, n. 33, p. 257-270, 2010.

DONABEDIAN, A. An introduction to quality assurance in health care. Oxford: Oxford University, 2003.

FAVORITO, L. et al. Estudo epidemiológico sobre câncer de pênis no Brasil. International Brazilian Journal of Urology, São Paulo, v. 34, n. 5, p. 587593, 2008.
FIGUEIREDO, W. S. Assistência à saúde dos homens: um desafio para os serviços de atenção primária. Ciência \& Saúde Coletiva, Rio de Janeiro, v. 10, n. 1, p. 105-109, 2005.

FIGUEIREDO, W. S.; SCHRAIBER, L. B. Concepções de gênero de homens usuários e profissionais de saúde de serviços de atenção primária e os possíveis impactos na saúde da população masculina, São Paulo, Brasil. Ciência ¿ Saúde Coletiva, Rio de Janeiro, v. 16, p. 935-944, 2011. Suplemento 1.

GERHARDT, T. E. Itinerários terapêuticos em situações de pobreza: diversidade e pluralidade. Cadernos de Saúde Pública, Rio de Janeiro, v. 22, n. 11, p. 2449-2463, 2006.

GERHARDT, T. E. et al. Determinantes sociais e práticas avaliativas de integralidade em saúde: pensando a situação de adoecimento crônico em um contexto rural. In: PINHEIRO, R.; MARTINS, P. H. (Org.). Avaliação em saúde na perspectiva do usuário: abordagem multicêntrica. Rio de Janeiro: CEPESC, 2009. p. 287-298.

GERHARDT, T. E. et al. Utilização de serviços de saúde de atenção básica em municípios da metade sul do Rio Grande do Sul: análise baseada em sistemas de informação. Ciência \& Saúde Coletiva, Rio de Janeiro, v. 16, p. 1221-1232, 2011. Suplemento 1. GOMES, R.; NASCIMENTO, E. F.; ARAÚJO, F. C. Por que os homens buscam menos os serviços de saúde do que as mulheres?: as explicações de homens com baixa escolaridade e homens com ensino superior. Cadernos de Saúde Pública, Rio de Janeiro, v. 23, n. 3, p. 565-574, 2007.

KASSOUF, A. L. Acesso aos serviços de saúde nas áreas urbana e rural do Brasil. Revista de Economia e Sociologia Rural, São Paulo, v. 43, n. 1, p. 29-44, 2005.

LAURENTI, R.; MELLO-JORGE, M. H. P.; GOTLIEB, S. L. D. Perfil epidemiológico da morbimortalidade masculina. Ciência \& Saúde Coletiva, Rio de Janeiro, v. 10, n. 1, p. 35-46, 2005.

LUZ, M. T. Natural, racional, social: razão médica e racionalidade científica moderna. Rio de Janeiro: Campus, 1988. 
MINAYO, M. C. S. O desafio do conhecimento: pesquisa qualitativa em saúde. São Paulo: Hucitec, 2010.

MORAIS, E. P.; RODRIGUES, R. A. P.; GERHARDT, T. E. Os idosos mais velhos no meio rural: realidade de vida e saúde de uma população do interior gaúcho. Texto \& Contexto - Enfermagem, Florianópolis, v. 17, n. 2, p. 374-383, 2008.

NARDI, H. C. $\mathrm{O}$ ethos masculino e o adoecimento relacionado ao trabalho. In: DUARTE, L. F. D.; LEAL, O. F. (Org.). Doença, sofrimento, perturbação: perspectivas etnográficas. Rio de Janeiro: Fiocruz, 1998. p. 95-104.

OLIVEIRA, F. A. Concepções de doença: o que os serviços de saúde têm a ver com isto? In: DUARTE, L. F. D.; LEAL, O. F. (Org.). Doença, sofrimento, perturbação: perspectivas etnográficas. Rio de Janeiro: Fiocruz, 1998. p. 81-94.

PINHEIRO, R. S. et al. Gênero, morbidade, acesso e utilização de serviços de saúde no Brasil. Ciência \& Saúde Coletiva, Rio de Janeiro, v. 7, n. 4, p. 687707, 2002.

ROESE, A.; GERHARDT, T. E. Fluxos e utilização de serviços de saúde: mobilidade dos usuários de média complexidade. Revista Gaúcha de Enfermagem, Porto Alegre, v. 29, n. 2, p. 221-229, 2008.
RUIZ, E. N. F. A mediação social no cuidado ao adoecimento crônico no meio rural: a constituição, a dinâmica e a implicação das relações para a saúde. 2013. Tese (Doutorado em Desenvolvimento Rural) - Universidade Federal do Rio Grande do Sul, Porto Alegre, 2013.

SCHRAIBER, L. B. et al. Necessidades de saúde e masculinidades: atenção primária no cuidado aos homens. Cadernos de Saúde Pública, Rio de Janeiro, v. 26, n. 5, p. 961-970, 2010.

SEVERINO, A. J. Metodologia do trabalho científico. São Paulo: Cortez, 2007.

SOUZA, A. C. de; LOPES, M. J. M. Práticas terapêuticas entre idosos de Porto Alegre: uma abordagem qualitativa. Revista da Escola de Enfermagem da USP, São Paulo, v. 41, n. 1, p. 52-56, 2007.

TONELI, M. J. F.; SOUZA, M. G. C.; MÜLLER, R. C. F. Masculinidades e práticas de saúde: retratos da experiência de pesquisa em Florianópolis/SC. Physis: Revista de Saúde Coletiva, Rio de Janeiro, v. 20, n. 3, p. 973-994, 2010.

TRAD, L. A. B. et al. Itinerários terapêuticos face à hipertensão arterial em famílias de classe popular. Cadernos de Saúde Pública, Rio de Janeiro, v. 26, n. 4, p. 797-806, 2010.

TRAVASSOS, C.; MARTINS, M. Uma revisão sobre o conceito de acesso e utilização de serviços de saúde. Cadernos de Saúde Pública, Rio de Janeiro, v. 20, p. 190-198, 2004. Suplemento 2. 